\section{What is already known on this topic}

Decision aids can help patients to participate in their care

Ten evidence based leaflets (Informed Choice) are used by maternity services in the United Kingdom to promote informed choice in women using these services

\section{What this paper adds}

The leaflets did not help to promote informed choice in maternity care

Decision aids may not be effective in the real world

\section{Practicality and quality of implementation}

We carried out this trial in everyday practice. We included thousands of women who might have received the 10 leaflets, but only $70 \%$ reported receiving one of them. Studies reported in the systematic review of decision aids were explanatory trials, with the implicit assumption that all patients received the intervention. ${ }^{3}$ One conclusion might be that the systematic review showed that decision aids can be effective under certain circumstances but that our study showed that they are not necessarily effective in the real world. ${ }^{7}$ The pragmatic nature of our design may have affected the outcome, but that outcome represents a true picture of the impact of introducing the leaflets into routine practice.

We thank midwives, managers, and administrative staff in the maternity units in Wales (unnamed to ensure confidentiality of participating units), who worked so hard to help us with data collection. We thank the thousands of women who completed our questionnaires at such an important time in their lives. Contributors: See bmj.com

Funding: This work was commissioned by the NHS Centre of Reviews and Dissemination and funded by the Department of Health. The views expressed here are those of the authors and not necessarily those of the Department of Health.

Competing interests: None declared.

Charles C, Gafni A, Whelan T. International conference on treatment decision-making in the clinical encounter [editorial]. Health Expect 2000;3:1-5.

2 Entwistle VA. Supporting and resourcing treatment decision-making: some policy considerations. Health Expect 2000;3:77-85.

3 O'Connor AM, Rostom A, Fiset V, Tetroe J, Entwistle V, LlewellynThomas H, et al. Decision aids for patients facing health treatment or screening decisions: systematic review. BMJ 1999;319:731-4

4 Stapleton H, Kirkham M, Thomas G. Qualitative study of evidence based leaflets in maternity care. BMJ 2002;324:639-43.

5 Degner L, Sloan JA, Venkatesh P. The control preference scale. Can J Nurs Res 1997;29:21-43.

6 Kirkham M, Stapleton H, eds. Informed choice in maternity care: an evaluation of evidence based leaflets. York: University of York, 2001 (report 20).

7 Holmes-Rovner M, Valade D, Orlowski C, Draus C, Nabozny-Valerio B, Keiser S. Implementing shared decision-making in routine practice: barriers and opportunities. Health Expect 2000;3:182-91.

(Accepted 5 October 2001)

\title{
Trends in demand for emergency ambulance services in Wiltshire over nine years: observational study
}

\author{
Hannah Wrigley, Steve George, Helen Smith, Helen Snooks, Alan Glasper, Eileen Thomas
}

Health Care

Research Unit,

Community

Clinical Sciences

Division, School of

Medicine,

University of

Southampton,

Southampton

SO16 6YD

Hannah Wrigley

research assistant

Steve George

reader in public

health

continued over

BMJ 2002;324:646-7

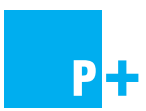

Extra tables and a methodological supplement appear on bmj.com
Demand for emergency medical services in the United Kingdom is rising. ${ }^{1}$ Research into the type of patients transported by emergency ambulances and the severity of their illness has tended to focus on identifying people who use the service inappropriately rather than factors influencing demand, and our understanding of the increase in demand is poor. ${ }^{23}$

In Wiltshire, a largely rural county in the south west of England, the number of emergency transports of patients increased from 11268 in 1988 to 16814 in 1996, a crude increase of $49 \%{ }^{4}$ This increase is often attributed to general practitioners redirecting patients with urgent problems to the ambulance service, particularly out of surgery hours. Over the same period, however, urgent transports booked by general practitioners rather than in response to a 999 call rose from 9982 to 13951 (40\%). We examined the reasons for this rise.

\section{Methods and results}

We conducted a retrospective analysis of emergency ambulance despatches using a random sample of records held by Wiltshire Ambulance Service NHS Trust. From each year in nine years' records (1988-96) we sampled 14 days, stratified by season, providing a dataset of 126 days of calls. Data were drawn from AS1 forms (completed by call takers) and from patient report forms (completed by paramedics). We used the system of call classification used by the trust to categorise data on the nature of incidents for analysis. We used indirect age standardisation based on the year with the most complete age data (1994) to account for demographic changes over the nine years (see methodological supplement on bmj.com). We calculated significance of trends with EpiInfo 6.03, using $\chi^{2}$ for trend.

Our sample contained details of 6100 calls relating to 5821 incidents. For 1225 (21\%) of these, patient report forms rather than AS1 forms had been filled in. The table shows the numbers of vehicles despatched, incidents, and patients transported in each year.

A $72 \%$ increase in incidents attended over nine years reduced to $53 \%$ after standardisation for age. The proportion of incidents in response to a call from a general practitioner, or incidents where one was present, remained fairly constant over the study period, whereas the proportion of calls made by patients and relatives rose from $11.8 \%$ to $20.1 \%$ (see tables A and B on bmj.com). Calls from other emergency services peaked in 1990. The category showing an increase out of line with that seen overall was "sudden illness at 
Use of ambulance services in Wiltshire. Values are numbers (percentages) unless otherwise specified

\begin{tabular}{|c|c|c|c|c|c|c|c|c|c|c|}
\hline Incident ( $\mathrm{n}=5821)$ & $\begin{array}{c}1988 \\
(n=474)\end{array}$ & $\begin{array}{c}1989 \\
(n=546)\end{array}$ & $\begin{array}{c}1990 \\
(n=590)\end{array}$ & $\begin{array}{c}1991 \\
(\mathrm{n}=577)\end{array}$ & $\begin{array}{c}1992 \\
(n=580)\end{array}$ & $\begin{array}{c}1993 \\
(n=709)\end{array}$ & $\begin{array}{c}1994 \\
(n=773)\end{array}$ & $\begin{array}{c}1995 \\
(\mathrm{n}=759)\end{array}$ & $\begin{array}{c}1996 \\
(n=813)\end{array}$ & $\begin{array}{c}\text { P value } \\
\text { ( } \chi^{2} \text { for trend } \\
\text { over time })\end{array}$ \\
\hline GP made call & $31(6.5)$ & $26(4.8)$ & $29(4.9)$ & $23(4.0)$ & $25(4.3)$ & $32(4.5)$ & $41(5.3)$ & $39(5.1)$ & $36(4.4)$ & $0.49(0.47)$ \\
\hline GP was present & $46(9.7)$ & $49(9.0)$ & $43(7.3)$ & $43(7.5)$ & $52(9.0)$ & $52(7.3)$ & $87(11.3)$ & $72(9.5)$ & $83(10.2)$ & $0.12(2.49)$ \\
\hline \multicolumn{11}{|l|}{ Category of incident: } \\
\hline Sudden illness at home & $106(22.4)$ & $101(18.5)$ & $123(20.1)$ & $126(21.8)$ & $146(25.2)$ & $180(25.4)$ & $219(28.3)$ & $184(24.2)$ & $228(28.0)$ & $<0.0001(20.43)$ \\
\hline $\begin{array}{l}\text { Sudden illness, } \\
\text { public place }\end{array}$ & $73(15.4)$ & $80(14.7)$ & $74(12.5)$ & $88(15.3)$ & $93(16.0)$ & $101(14.3)$ & $109(14.1)$ & $132(17.4)$ & $139(17.1)$ & $3.04(0.08)$ \\
\hline $\begin{array}{l}\text { Obstetric or } \\
\text { gynaecological problem }\end{array}$ & $20(4.2)$ & $22(4.0)$ & $14(2.4)$ & $28(4.9)$ & $22(3.8)$ & $22(3.1)$ & $20(2.6)$ & $27(3.6)$ & $21(2.6)$ & $0.09(2.81)$ \\
\hline Overdose or self harm & $29(6.1)$ & $36(6.6)$ & $29(4.9)$ & $32(5.6)$ & $41(7.1)$ & $52(7.3)$ & $53(6.9)$ & $39(5.1)$ & $54(6.6)$ & $0.66(0.19)$ \\
\hline Fall (assistance required) & $5(1.1)$ & $7(1.3)$ & $6(1.0)$ & $12(2.1)$ & $6(1.0)$ & $12(1.7)$ & $11(1.4)$ & $6(0.8)$ & $10(1.2)$ & $0.82(0.05)$ \\
\hline Accident at home & $42(8.9)$ & $37(6.8)$ & $62(10.5)$ & $59(10.2)$ & $64(11.0)$ & $72(10.2)$ & $80(10.4)$ & $76(10.0)$ & $73(9.0)$ & $0.41(0.69)$ \\
\hline Accident in public place & $41(8.7)$ & $51(9.3)$ & $41(7.0)$ & $28(4.9)$ & $47(8.1)$ & $57(8.0)$ & $51(6.6)$ & $56(7.4)$ & $72(8.9)$ & $0.97(0.00)$ \\
\hline Road traffic accident & $86(18.1)$ & $108(19.8)$ & $110(18.7)$ & $96(16.6)$ & $64(11.0)$ & $112(15.8)$ & $76(9.8)$ & $115(15.2)$ & $112(13.8)$ & $<0.0001(18.90)$ \\
\hline Sports accident & $12(2.5)$ & $7(1.3)$ & $9(1.5)$ & $11(1.9)$ & $12(2.1)$ & $14(2.0)$ & $11(1.4)$ & $10(1.3)$ & $9(1.1)$ & $0.14(2.21)$ \\
\hline Industrial accident & $9(1.9)$ & $9(1.7)$ & $5(0.9)$ & $8(1.4)$ & $8(1.4)$ & $11(1.6)$ & $11(1.4)$ & $13(1.7)$ & $10(1.2)$ & $0.83(0.05)$ \\
\hline Assault & $14(3.0)$ & $20(3.7)$ & $22(3.7)$ & $22(3.8)$ & $13(2.2)$ & $17(2.4)$ & $32(4.1)$ & $23(3.0)$ & $21(2.6)$ & $0.43(0.62)$ \\
\hline Drunkenness & $4(0.8)$ & $4(0.7)$ & $11(1.9)$ & $11(1.9)$ & $9(1.6)$ & $5(0.7)$ & $21(2.7)$ & $16(2.1)$ & $11(1.4)$ & $0.11(2.52)$ \\
\hline Fire call & $6(1.3)$ & $25(4.6)$ & $31(5.3)$ & $36(6.2)$ & $28(4.8)$ & $29(4.1)$ & $28(3.6)$ & $37(4.9)$ & $15(1.9)$ & $0.28(1.18)$ \\
\hline Hoax call & 0 & 0 & 0 & 0 & 0 & 0 & 0 & 0 & $1(0.1)$ & - \\
\hline Total valid cases & 447 & 507 & 537 & 557 & 553 & 684 & 722 & 734 & 776 & - \\
\hline Missing or unclassifiable & 27 & 39 & 53 & 20 & 27 & 25 & 51 & 25 & 37 & - \\
\hline
\end{tabular}

home." In this category, incidents described in general terms such as "collapse" fell from $35 \%$ to $20 \%$, whereas those attributed more specifically to cardiac problems rose from $22 \%$ to $31 \%$ and those attributed to respiratory problems from $12 \%$ to $21 \%$ (see table $\mathrm{C}$ on bmj.com).

\section{Comment}

Demand for emergency ambulances has risen, and there is evidence that people are using more specific terminology to describe emergency incidents. We found no evidence of a transfer of general practitioners' workload to the emergency ambulance service. The fall in mortality across all age groups in Western society leads us to conclude that the demand threshold is falling. ${ }^{5}$

Callers' perceptions of urgency are known to be unreliable, and a wider range of responses from service providers may be the most appropriate way to manage rising demand. ${ }^{3}$ The integration of the gateway to primary care out of hours with NHS Direct might provide one way of accomplishing this. Research identifying influences on callers' perceptions of urgency is necessary if we are to improve our understanding of the demand for emergency care and our ability to plan for the future.

We thank members of Wiltshire Ambulance Services Trust who provided data, tea, and moral support during long days of searching for records. We also thank the NHS Executive South and West Research and Development Directorate for funding this study. The opinions expressed, however, are those of the authors alone.

Contributors: SG, H Smith, AG, and ET obtained funding for this study. HW collected and categorised data. HW and SG undertook the analysis with advice from all authors. Specialist advice on ambulance services was provided by $\mathrm{H}$ Snooks. All authors participated in the interpretation of findings, writing up and editing of the paper. SG is the guarantor.

Competing interests: None declared.

1 Hallam L. Primary medical care outside normal working hours: review of published work. BMJ 1994;308:249-53.
2 Wrigley H, Snooks H, Thomas E, Smith H, Glasper A, George S. Epidemiology and demography of emergency ambulance calls: a review. Pre miology and demography of

3 Snooks H, Wrigley H, George S, Thomas E, Smith H, Glasper A. Appropriateness of use of emergency ambulances. J Accid Emerg Med 1998;15:212-5.

4 Wiltshire Ambulance Service NHS Trust. Summary of activity: patients and mileage-1994/95. Chippenham: Wiltshire Ambulance Service NHS Trust, 1995

5 Tuljapurkar S, Li N, Boe C. A universal pattern of mortality decline in the G7 countries. Nature 2000;405:789-92.

(Accepted 20 September 2001)

\section{Corrections and clarifications}

Filler

A missing letter escaped our notice in the endpiece "Choosing a doctor" by W H Auden (5 January, p 38). The first line should read: "Give me a doctor partridge-plump [not "partridge-pump"].

\section{Minerva}

Having corresponded with author David Bourne about the details relating to the Minerva picture (2 February, p 308), we then forgot to include the name of his coauthor, P Bannister, consultant physician and geriatrician at Manchester Royal Infirmary, Manchester M13 9WL. We apologise for this omission.

Biological warfare and bioterrorism

In this article by Nicholas J Beeching and colleagues (9 February, pp 336-9) we wrongly attributed the street depicted on p 337 to North Korea. The street is in fact in Seoul, South Korea.

Children of war: the real casualties of the Afghan conflict Captions to pictures can be bothersome for us. We mixed up our countries in the caption to figure 2 in this article by Zulfiqar Ahmed Bhutta (9 February, pp 349-52). Baluchistan and North-West Frontier Province are both in Pakistan, not Afghanistan. The second sentence in the caption should therefore read: "The Taliban movement arose among Afghan children attending madrassahs in neighbouring Baluchistan and North-West Frontier Province, Pakistan."
Academic

Department of Primary Medical Care, Community Clinical Sciences Division, School of Medicine,

University of

Southampton

Helen Smith reader in primary care medicine

School of Nursing,

University of Southampton

Alan Glasper professor of nursing

studies

University of Wales, Swansea, Wales SA2 8PP

Helen Snooks senior lecturer in health and social care research

Portsmouth Health Care NHS Trust,

Portsmouth PO3 6DP

Eileen Thomas executive director of nursing

Correspondence to: S George pluto@soton.ac.uk 